\title{
STATIC ATOMIC DISPLACEMENTS IN CRYSTALLINE SOLID SOLUTION ALLOYS
}

GENE ICE*, CULLIE SPARKS*, J. LEE ROBERTSON*, J. ERNEST EPPERSON*, AND XIAOGANG JIANG**,

*Oak Ridge National Laboratory, P.O. Box 2008, Oak Ridge, TN 37831-6118

**Sandia Livermore National Laboratory, P.O. Box 969, Livermore CA 94550

\section{ABSTRACT}

Atom size differences induce static displacements from an average alloy lattice and play an important role in controlling alloy phase stability and properties. The details of this role however, are difficult to study; chemical order and displacements are strongly interrelated and static displacements are hard to measure. Diffuse x-ray scattering measurements with tunablesynchrotron radiation can now measure element-specific static displacernents with an accuracy of $\pm 0.1 \mathrm{pm}$ and can simultaneously measure local chemical order out to 20 shells or more. Ideal alloys for diffuse scattering analysis with synchrotron radiation, are those that have previously been the most intractable: alloys with small $\mathrm{Z}$ contrast, alloys with only local order and alloys with small size differences. The combination of precise characterization of local chemical order and precise measurement of static displacement provides new information that challenges existing alloy models. We report on an ongoing systematic study of static displacements in the $\mathrm{Fe} / \mathrm{Ni} / \mathrm{Cr}$ alloys and compare the observed static displacements to the static displacements predicted by current theories. The availability of more brilliant 3 rd generation hard $\mathrm{x}$-ray sources will greatly enhance these measurements.

\section{INTRODUCTION}

Three factors govern the structure of alloys and, hence, their physical and chemical properties. These factors are atomic size, relative valency and electrochemistry. ${ }^{1.2}$ Although the theoretical treatment of valency and electrochemistry is included in ab initio alloy modeling, the effect of displacements from the average lattice is more difficult to treat with band theory methods, and with a few exceptions $s^{3-6}$, has been largely ignored. The $\mathrm{Fe} / \mathrm{Ni} / \mathrm{Cr}$ alloys are particularly sensitive to atomic displacements because of the interaction of magnetism with chemical order and lattice dimensions. ${ }^{7,8}$ However, the chemical order and chemically specific static displacements have been difficult to measure in $\mathrm{Fe} / \mathrm{Ni} / \mathrm{Cr}$ alloys because the $\mathrm{x}$-ray and neutron contrast between these elements is small. ${ }^{9}$

The recent availability of synchrotron radiation has now revolutionized the measurement of static atomic displacements in solid solution alloys. ${ }^{10-13}$ In dilute alloys, $x$-ray absorption fine structure (XAFS) methods can measure displacements with precisions on the order of $1 \mathrm{pm}$. XAFS provides valuable information on chemically specific bond distances for alloys with large atomic size differences in dilute systems. Recent XAFS measurements have stimulated interest in the role of chemical defects on lattice size. For example, the topological rigidity parameter, $a^{* *}$, has been defined to distinguish between global lattice expansion/contraction with little local distortion of the bond angles (rigid lattice, $a^{* *}=0$ ) and local or short-ranged lattice expansion/contraction with distinct bond lengths (floppy limit, $a^{* *}=1$ ). ${ }^{4}$

Diffuse $\mathrm{x}$-ray scattering with synchrotron radiation is even more sensitive than XAFS to static displacements; displacements have been measured in binary alloys with uncertainties to $\sim 0.1$ pm. ${ }^{15-18}$ With third generation sources, diffuse $x$-ray scattering will be capable of detecting the sign (expansion or contraction) of static displacements to at least $0.01 \mathrm{pm}$. These direct measurements of chemically specific static displacements provide a powerful test of theoretical attempts to understand the role of atomic size in alloy phase stability and properties. Diffuse scattering measurements go beyond XAFS measurements because they are more sensitive to nearneighbor displacements and because they can measure out to five or more atomic shells. Diffuse $\mathrm{x}$ -

\section{DISTRIBUTON OF MIS DOCUMENT IS UNLMTED}


ray scattering also provides the chemical pair-correlations for non-dilute systems with substantial order or clustering tendency.

Key to the diffuse scattering measurements is the availability of intense and tunable synchrotron radiation. Only synchrotron radiation provides sufficient tunable intensity for diffuse scattering. With an intense and tunable synchrotron source the scattering contrast can be varied by tuning the $x$-ray energy near to an absorption edge; this is especially important for elements nearby in the periodic table where, except for some heroic neutron measurements, local structure has been virtually invisible.

We report here on an ongoing systematic study of atomic size in the $\mathrm{Fe} / \mathrm{Ni} / \mathrm{Cr}$ alloys and show how diffuse $\mathrm{x}$-ray scattering measurements challenge the results of average potential or equivalent theories. Current efforts to model static displacements are summarized and future tests of theoretical models are presented.

\section{THEORY AND EXPERIMENT}

The experiments were performed on beamline X14 at the National Synchrotron Light Source. ${ }^{19}$ Binary alloy single crystals with $\mathrm{Fe}, \mathrm{Ni}$ or $\mathrm{Cr}$ were cut with the surface normal near the (321) orientation. This orientation allowed the $x$-ray scattering to be probed with a maximum entrance and exit angle from the crystals in the symmetric geometry. ${ }^{20}$ The crystals were homogenized at high temperature then quenched from above the long range ordering temperature, polished and etched. Monochromatic x-rays from a double-crystal sagittal-focusing monochromator were focused onto a polished flat single crystal in the symmetric geometry. The beam size at the sample was about $1 \mathrm{~mm} \times 2 \mathrm{~mm}$. The sample was oriented by a split-circle diffractometer with a detector range to $2 \theta=170^{\circ}$. The large $2 \theta$ range maximized the volume of reciprocal space that could be measured; large $2 \theta$ is particularly important for materials with low energy absorption edges ( $<15$ $\mathrm{keV}$ ), which restrict the accessible reciprocal space. ${ }^{20}$

The X-ray scattering was measured at three $x$-ray energies: (1) $20 \mathrm{eV}$ below the edge of one element, (2) $20 \mathrm{eV}$ below the edge of the second element and (3) at an intermediate energy where the $x$-ray scattering contrast was small $\left(f_{A} \sim f_{B}\right)$. Because two of the three measurements were made very near elemental absorption edges, a graphite spectrometer was used to separate the inelastic $x$ ray scattering (i.e. resonant Raman scattering) from the elastic scattering. ${ }^{21}$
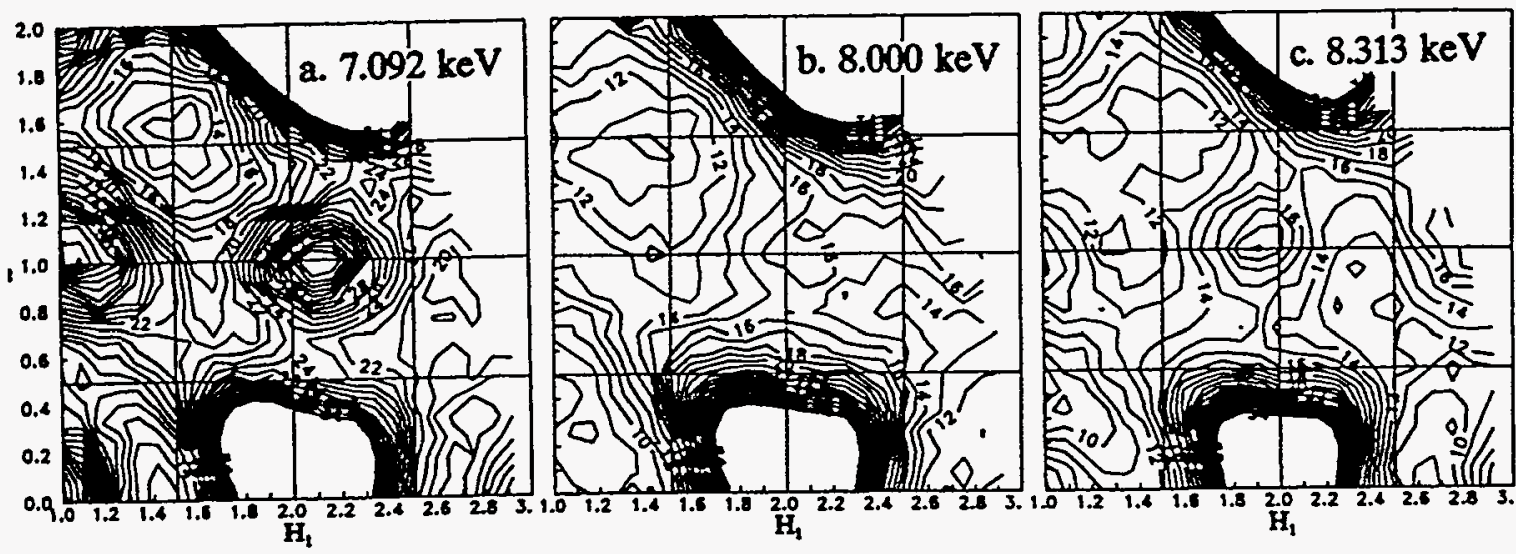

Fig. 1 Diffuse $x$-ray scattering intensities in the $\mathrm{H}_{3}=0$ plane collected with $\mathrm{x}$-ray energies of (a) 7.092 (b) 8.000 , and (c) $8.313 \mathrm{keV}$ for the alloy $\mathrm{Fe}_{22.5} \mathrm{Ni}_{77.5}$.

The x-ray diffraction patterns for solid solution alloys consist both of sharp fundamental Bragg reflections and a diffuse so called "Laue" scattering (Fig. 1). Quite generally in the kinematic 
approximation, the $x$-ray scattering intensity $I_{T}$ from a binary alloy can be described by a double sum over all lattice sites p,q.

$$
I_{T}=\sum_{p} \sum_{q} f_{p} f_{q} e^{i k \bullet\left(R_{p}-R_{q}\right)} e^{i k \bullet\left(\delta_{p}-\delta_{q}\right)}
$$

Here the f's are the atomic scattering factors, the R's are the average lattice site positions, the $\delta$ 's are the displacements from the average lattice sites and $\mathbf{k}$ is the usual reciprocal lattice vector. The total scattering intensity can be separated into a Bragg scattering component (scales as the square of the average atomic scattering factor of the constituent atoms), and a Laue component (scales as the square of the difference in atomic scattering factors).

$$
\begin{aligned}
& I_{T}=\left(c_{a} f_{a}+c_{b} f_{b}\right)^{2} \sum_{p} \sum_{q} e^{i k \bullet\left(R_{p}-R_{q}\right)} e^{i k \bullet\left(\delta_{p}-\delta_{q}\right)} \\
& +\sum_{p} \sum_{q}\left(f_{p} f_{q}-\left(c_{a} f_{a}+c_{b} f_{b}\right)^{2}\right) e^{i k \bullet\left(R_{p}-R_{q}\right)} e^{i k \bullet\left(\delta_{p}-\delta_{q}\right)} \\
& =I_{\text {Bragg }}+I_{\text {Laue }}
\end{aligned}
$$

Here $c_{a}$ and $c_{b}$ are the elemental concentrations of atoms $a$ and $b$. Both static and dynamical displacements or thermal diffuse scattering (TDS) distributes the Bragg intensity away from the Bragg peaks. For the $\mathrm{Fe}, \mathrm{Ni}$ and $\mathrm{Cr}$ alloys, the thermal displacements are roughly independent of elemental identity and the TDS scattering scales linearly with the average scattering factor. For $\mathrm{Fe} / \mathrm{Ni} / \mathrm{Cr}$ alloys TDS can therefore be measured precisely in the null Laue condition, $\mathrm{f}_{\mathrm{A}} \sim \mathrm{f}_{\mathrm{B}}$. The TDS contribution to diffuse scattering can then be removed from the diffuse scattering maps at other $\mathrm{X}$-ray energies by scaling the Bragg component with the average scattering factor. ${ }^{15-18}$.

The distribution of Laue scattering depends on chemical order, thermal and static displacments. If there is perfect order among the atoms of the solid solution, the Laue scattering is gathered into sharp superlattice reflections. If the tendency to order exists for only a few near neighbors, then the Laue scattering is diffusely distributed depending on the degree of local correlations. The distribution of Laue scattering through reciprocal space is spread by static and thermal displacements, but the thermal displacements usually have only a small effect for short-rangeordered alloys.

Our interest is in measuring the local or short-ranged correlations and in determining the static displacements caused by differences in atomic size and bonding that introduces local strain from an average lattice. We remove the Bragg component of the diffuse scattering through a null Laue measurement $\left(f_{A} \sim f_{B}\right)$ and expand the Laue component to first order in static displacements. This approximation is adequate for $\mathrm{Fe} / \mathrm{Ni} / \mathrm{Cr}$ alloys where the atomic size difference is small. More complete discussions of the theory and data analysis with synchrotron radiation are given in references $15-18$.

\section{RESULTS AND DISCUSSION}

$\mathrm{Fe}_{22.5} \mathrm{Ni}_{77.5}$ and $\mathrm{Fe}_{46.5} \mathrm{Ni}_{53.5}$

Measurements to date have recovered the correlations in $\mathrm{Fe}_{22.5} \mathrm{Ni}_{77.5}, \mathrm{Fe}_{46.5} \mathrm{Ni}_{53.5}, \mathrm{Ni}_{80} \mathrm{Cr}_{20}$ and $\mathrm{Cr}_{47} \mathrm{Fe}_{53}$. The diffuse scattering maps in the $\mathrm{H}_{3}=0$ plane for $\mathrm{Fe}_{22.5} \mathrm{Ni}_{77.5}$ is shown in Fig. 1. At $7.092 \mathrm{keV} \mathrm{f} \mathrm{Ni}_{\mathrm{Fe}}-\mathrm{f}_{\mathrm{Fe}}$ is positive and as a result, the displacements of the SRO peaks from the superlattice sites are opposite in sign from the displacements observed at $8.313 \mathrm{keV}$ where $\mathrm{f}_{\mathrm{Ni}}-\mathrm{f}_{\mathrm{Fe}}$ is 
negative. At $8.000 \mathrm{keV}$ the $\mathrm{x}$-ray scattering contrast is small and is primarily due to the imaginary part of the X-ray scattering factor; at $8.000 \mathrm{keV}$ no short-range-order scattering is evident due to the negligibly small Laue component of the $x$-ray scattering intensity. This qualitiative behavior of the diffuse scattering pattern with scattering contrast is the same for the three short-range ordering alloys studied: $\mathrm{Fe}_{22.5} \mathrm{Ni}_{77.5}, \mathrm{Fe}_{46.5} \mathrm{Ni}_{53.5}$ and $\mathrm{Cr}_{20} \mathrm{Ni}_{80}$.

The binary static displacements for $\mathrm{Fe}_{46.5} \mathrm{Ni}_{53.5}$ quenched from $600^{\circ} \mathrm{C}$ is shown in Fig. $2 \mathrm{~A}$. $\mathrm{Fe}_{465} \mathrm{Ni}_{53.5}$ quenched from $600^{\circ} \mathrm{C}$ is weakly ordering. ${ }^{18}$ The static displacements indicate that $\mathrm{Ni}$ $\mathrm{Ni}$ pairs lie close to the average lattice spacing while first neighbor $\mathrm{Fe}-\mathrm{Fe}$ pair are farther apart than predicted from the average lattice and $\mathrm{Ni}$-Fe first neighbor pairs are closer together than predicted from the average lattice. Second near neighbor displacements are also large and are in the opposite direction from the first neighbor displacements. This can partially be explained by the propagation of first neighbor displacements through the local ordering; Fe-Fe second neighbors will predominantly have a $\mathrm{Ni}$ first neighbor between them which shrinks the local lattice. ${ }^{22}$ Most striking is the fact that for all ordering alloys studied the near-neighbor $\mathrm{Fe}-\mathrm{Ni}$ bond distance is the smallest of the three possible bond distances (Fig. 2A,2B and 2C) This behavior cannot be predicted by theoretical models which use average potentials or spring constant models which average the force constants connecting the atoms.
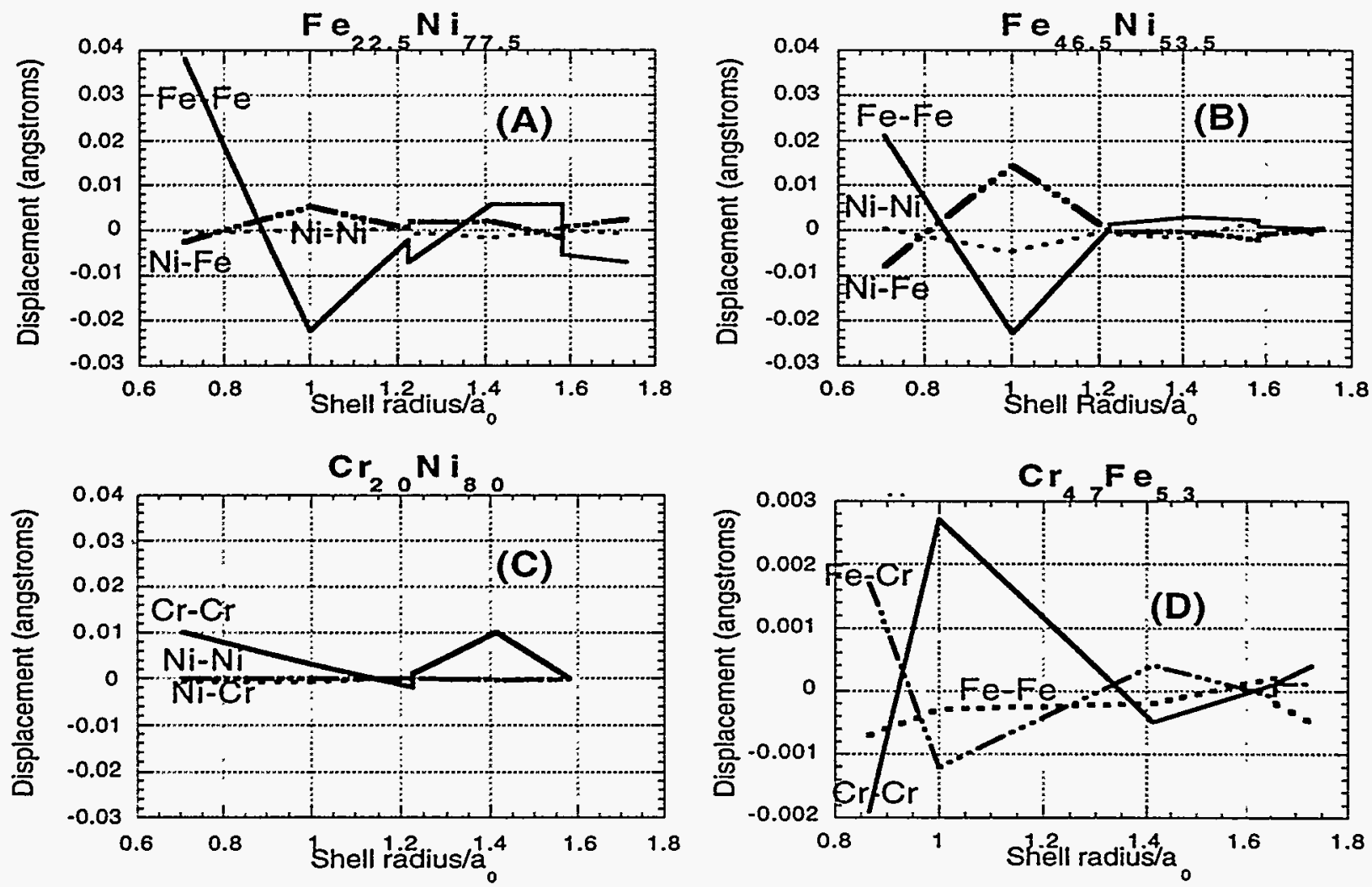

Fig. 2 Displacement from the average lattice sites for chemically specific pairs. Shell radius divided by the lattice parameter $a_{0}$ becomes 1 for second neighbors (seperated by the cube edge).

New theoretical models are needed to predict this behavior. Hartley ${ }^{23}$ has proposed a phenomenological model which assumes concentration independent pair-specific bond distances between atoms in an alloy. This is similar to the topological rigidity model $\left(\mathrm{a}^{* *}=1\right)$ except that the 
unlike pair bond distance can deviate from the average of the like pair distances. This model can account for unlike-pair bond distances smaller than the average of the like distances. Smaller than average distances are associated with an ordering tendency and larger than average distances are associated with clustering. The Hartley model, however, does not account for changes in the measured bond distances arising from changes in elemental concentration, and cannot explain topological rigidity less than unity $\left(a^{* *}<1\right)$.

Chakraborty ${ }^{6}$ has proposed a compressible Ising model which can reproduce the observed static displacements. In this model there is a "size effect" term which reflects the different size of the atoms and an "Ising" term which is sensitive to the distance dependent Ising interaction. This model reproduces our observed static displacements. For systems such as the $\mathrm{Fe} / \mathrm{Ni} / \mathrm{Cr}$ binary alloys where the "size" of the atoms is similar, the unlike pair displacements do not necessarily lie between the observed like-atom displacements. Although this model can reproduce the observed measurements, it depends on parameters from other models to explain the detailed physics of the observed displacements.

Small cluster calculations appear to be the most powerful tool presently available for studying the mechanisms behind the observed displacements. Of great interest is the relationship between local strains and overall lattice spacing. Recent calculations on small 12-18 atom clusters reproduce some of the observed displacement trends in $\mathrm{Fe}-\mathrm{Ni}$ alloys, but the results are difficult to interpret due to large surface and concentration effects. ${ }^{24}$ An imbedded cluster calculation could eliminate surface effects and lead to a much more complete understanding of the forces driving the observed static displacements.

$\mathrm{Cr}_{20} \mathrm{Ni}_{80}$ and $\mathrm{Fe}_{53} \mathrm{Cr}_{47}$

The FCC alloy $\mathrm{Cr}_{20} \mathrm{Ni}_{80}$ like the $\mathrm{Ni}-\mathrm{Fe}$ alloys above is observed to be weakly ordering. ${ }^{17}$ The static displacements are found to be extremely small (Fig. 2C) but also show a tendency for the unlike near neighbor bond distance to be smaller than either of the like near-neighbor bond distance. The $\mathrm{BCC} \mathrm{Fe}_{53} \mathrm{Cr}_{47}$ alloy however is weakly clustering. Here the unlike bond distances are found to be slightly larger than either of the like atom bond distances as shown in Fig. 2D.

\section{CONCLUSION}

Sensitive diffuse $\mathrm{x}$-ray scattering measurements of pair correlations in metal alloys illustrate that existing theoretical and phenomenological models are inadequate for understanding local strain in solid solution alloys. Where the atomic size difference is small, unlike near-neighbor bond distances are observed to be smaller than either like-neighbor bond distance for ordering alloys and larger than either like-neighbor bond distance for clustering alloys. Small cluster models appear to give the most insight as to the driving forces controlling the bond distances in the $\mathrm{Fe} / \mathrm{Ni} / \mathrm{Cr}$ binary alloys.

\section{ACKNOWLEDGMENTS}

Research performed in part at the Oak Ridge National Laboratory Beamline X14 at the NSLS, BNL sponsored by the Division of Materials Sciences and Division of Chemical Sciences, U.S. Dept. of Energy under contact DE-AC05-96OR22464 with Lockheed Martin Energy Research Corp. X. Jiang is supported by Sandia National Laboratory.

\section{REFERENCES}

1. F. Laves in, Theory of Alloys Phases, (American Society for Metals, Cleveland OH, 1956), p.124. 
2. W. B. Pearson in, A Handbook of Lattice Spacings and Structures of Metals (Pergamon Press, New York, NY, 1958), p. 19.

3. S. Froyen and C. Herring, J. App. Phys., 527165 (1981).

4. A. Zunger in Statics and Dynamics of Alloy Phase Transformations, eds. P. E. A. Turchi and A. Gonis, (Plenum, N.Y. 1994) .

5. N. Mousseau and M.F. Thorpe, Phys. Rev. B, 45, 2015 (1992).

6. B. Charkraborty, Europhys. Lett., 30531 (1995).

7. D. D. Johnson, F.J. Pinski and J.B. Stauton, J. Appl. Phys. 613715 (1987).

8. J. B. Staunton, D.D. Johnson and B.L. Gyorffy, J. Appl. Phys., 613693 (1987).

9. S. Lefebvre, F. Bley, M. Bessiere, M. Fayard, M. Roth and J. Cohen, Acta Cryst. A, 361 (1980).

10. G. Renaud, N. Motta, F. Lancon and M. Belakhovsky, Phys. Rev. B 385944 (1988).

11. U. Scheuer and B. Lengeler, Phys. Rev. B, 449883 (1991).

12. A. Balzarotti, N. Motta, A. Kisiel, M. Zimnal-Starnawska, M.T. Czyzyk and M. Podgorny, Phys. Rev. B, 317526 (1985).

13. D.B. Aldrich, R.J. Nemanich and D.E. Sayers Phys. Rev. B, 5015026 (1994).

14. Y. Cai and M.F. Thorpe, Phys. Rev. B, 4615872 (1992).

15. G.E. Ice, C.J. Sparks, A. Habenschuss and L.B. Shaffer, Phys. Rev. Lett., 68863 (1992).

16. L. Reinhard, J.L. Robertson, S.C. Moss, G.E. Ice, P. Zschack and C.J. Sparks, Phys. Rev. B, 452662 (1992).

17. B. Schönfeld, G.E. Ice, C.J. Sparks, H.G. Haubold, W. Schweika and L.B. Shaffer, Phys. Status Solidi. B, 183.79 (1994).

18. X. Jiang, G.E. Ice, C.J. Sparks, L. Robertson and P. Zschack, submitted Phys. Rev. B, (1996).

19. A. Habenschuss, G.E. Ice, C.J. Sparks, R. A. Neiser, Nucl. Inst. and Meth., A266 215 (1988).

20. G.E. Ice, C.J. Sparks and L. Shaffer, in Resonant Anomalous X-ray Scattering edited by G. Materlik, C.J. Sparks, and K. Fischer,(North Holland, Amsterdam ,1994) p.265.

21. G.E. Ice and C.J. Sparks, Nucl. Inst. and Meth., A291 110 (1990).

22. X. Jiang, private communication.

23. C.S. Hartley, in NATO-Advanced Research Workshop held at Florida Atlantic University, July 1993 (Boca Raton, FL: Kluwer Academic Publishers, Dordrecht, the Netherlands) p.271.

24. G.E. Ice, G. Painter, L. Shaffer and C.J. Sparks, Nanostructured Materials, 7 no.1-2, 147 (1996). 


\section{DISCLAIMER}

This report was prepared as an account of work sponsored by an agency of the United States Government. Neither the United States Government nor any agency thereof, nor any of their employees, makes any warranty, express or implied, or assumes any legal liability or responsibility for the accuracy, completeness, or usefulness of any information, apparatus, product, or process disclosed, or represents that its use would not infringe privately owned rights. Reference herein to any specific commercial product, process, or service by trade name, trademark, manufacturer, or otherwise does not necessarily constitute or imply its endorsement, recommendation, or favoring by the United States Government or any agency thereof. The views and opinions of authors expressed herein do not necessarily state or reflect those of the United States Government or any agency thereof. 